\title{
Effect of Work-Family Balance Policy on Job Selection and Social Sustainability: The Case of South Korea
}

\author{
Wang-Jin Yoo ${ }^{1}$ and Inha $\mathrm{Oh}^{2, *}$ \\ 1 Department of Industrial Engineering, Konkuk University, Gwangjin-gu, Seoul 143-701, Korea; \\ wjyoo@konkuk.ac.kr \\ 2 Department of Advanced Industry Fusion, Konkuk University, Gwangjin-gu, Seoul 143-701, Korea \\ * Correspondence: inha.oh@gmail.com; Tel.: +82-2-450-0446
}

Academic Editor: Giuseppe Ioppolo

Received: 3 February 2017; Accepted: 15 May 2017; Published: 18 May 2017

\begin{abstract}
South Korea needs to actively implement work-family balance policies to increase both the low employment rate of women and the low total fertility rate. This study analyzes the quantitative benefits that the implementation of work-family balance policies provides to employees and employers. We conducted a choice experiment that asked 633 participants about their stated preferences for a hypothetical company with different work-family balance practices. The analysis was performed by using a hierarchical Bayesian model that considered preference heterogeneity according to the respondents' characteristics. The results indicate that the availability of parental leave provides benefits equivalent to an increase of 5.80 million won in annual salary and that offering childcare in the workplace has an effect equivalent to an increase of 5.37 million won in annual salary. Further, low-income groups, women, the younger generation, and parents of preschool children are most sensitive to the policy. Finally, small and medium-sized enterprises are less desirable to work for than large companies, but the implementation of work-family balance policies could change this preference.
\end{abstract}

Keywords: work-family balance policy; South Korea; job selection; choice experiment; hierarchical Bayesian model

\section{Introduction}

South Korea, which has grown rapidly over a short period of time, has experienced difficulties in achieving sustainable development on various fronts. One of the symptoms of this has been the speed at which it is becoming an aged society because of extended life expectancy and the lowest total fertility rate among OECD member countries, and it is expected to become the world's most aged society around 2062 if this trend continues [1,2]. An aging population creates many challenges in terms of social sustainability such as lower tax revenue, a shrinking labor force, and increasing expenditure related to public health and infrastructure [3].

South Korea's low fertility rate stems, in part, from aspects of its social structure [4]. The country's rapid economic development has been accompanied by long working hours; the average annual working hours in 2012 were 2163 (the highest among OECD countries since the early 2000s), and promotions at South Korean companies largely hinge on long working hours with limited long-term vacations. Additionally, overtime and weekend work are common in the country; Shin pointed out that $45 \%$ of South Korean employees work more than $50 \mathrm{~h}$ per week, $63 \%$ of whom work more than five days per week and $13 \%$ work overtime more than three times per week, making juggling work and family difficult [5]. Consequently, the burden of bearing and rearing children lies on women who have traditionally taken the role, hampering their economic participation, especially in the mainstream job market. Women often have no option but to choose low wage, irregular jobs 
after childbirth, and some women who want to avoid this career interruption choose to hold onto their regular job positions without having a child. Indeed, the Hyundai Research Institute reported that South Korean parents have on average 0.76 fewer children than they would like to have [6].

To address the shrinking workforce caused by its aging population, South Korea must both increase the fertility rate of the country and encourage women's participation in the labor force. This is no easy task, however. For instance, a negative correlation was found between women's participation in the labor market and fertility rates for OECD countries in the 1980s, as women's high participation rates lowered fertility rates. However, as many countries promoted the employment of women as well as implemented policies to promote childbirth and work-family balance (WFB), the correlation between women's participation rates in the labor market and fertility rates turned positive among OECD countries in 2009 [7]. In particular, northern European countries that adopted well-coordinated and comprehensive WFB policies (e.g., pregnancy leave, parental leave, working hour reductions for childcare, flexible working hours, workplace childcare centers) simultaneously achieved higher employment rates for women and higher fertility rates. The implementation of WFB policies can increase fertility rates and women's economic participation by reducing the burden of childrearing and preventing career interruption [8,9].

In the case of South Korea, although these WFB policies are institutionally designed at the level of advanced countries, they are ineffectively implemented in practice [10]. The reason for the low implementation rate is that companies are more concerned with the additional cost (e.g., the cost of hiring replacement workers to cover for workers on parental leave) than the benefit deriving from practicing WFB policies. Therefore, the question of how much benefit in monetary terms WFB practices provide to workers arises. If this information is available, companies looking to attract talented workers can actively implement WFB policies that may offer job seekers an additional benefit and incentive along with a wage increase. Further, this information may also help design government support policies.

Based on the foregoing, the present study analyzes and compares workers' preference for a company that has WFB practices and a company that does not, using a choice experiment method. The contribution of our study is as follows. First, this study suggests a framework with which to estimate the quantitative benefits of various WFB policies, using the willingness to pay concept. The framework developed in this research can be readily applied to other Asian countries (e.g., China, Hong Kong, Taiwan, Singapore, and Japan) that suffer from similar work-family conflicts [11]. Second, this research applies the recently developed hierarchical Bayesian model [12], which allows us to observe and quantify the differences in sensitivity to WFB policies according to the demographic characteristics of respondents. Preferences for WFB policies are expected to vary according to gender, education level, income level, regional environment, and the other characteristics of individuals. Finally, this research suggests a strategy for small and medium-sized enterprises (SMEs) to attract talented workers by using WFB practices as an additional incentive.

The remainder of the paper is organized as follows. Section 2 introduces the current state of WFB policies in South Korea and examines the findings of previous studies. Section 3 explains the models and methods used in the study. Section 4 describes and discusses the results and, finally, the results are summarized and policy implications are drawn in Section 5.

\section{Research Background and Literature Review}

\subsection{WFB Policies in South Korea}

South Korea faces the dual problems of a low fertility rate and a low employment rate among women. South Korea's fertility rate has been at the lowest level among OECD members for more than 10 years, from 1.17 in 2002 to 1.21 in 2014 [2]. Meanwhile, South Korea's employment rate for women only rose by 1.5 percentage points from $52 \%$ in 2002 to $53.5 \%$ in 2012, which is lower than the OECD average rate of $57.2 \%$ in 2012. However, on closer inspection, the employment rates of women 
differ by age group. This phenomenon is described using the terms "M-curve" and "L-curve", as suggested by the National Assembly Budget Office [13]. The "M-curve" describes the phenomenon that the employment rate of women in their early 30s rapidly declines. The 2012 data for South Korea show that the employment rate of women in their late 20 s was $68 \%$, which is higher than the OECD average of $64 \%$ and shows a small difference of less than 10 percentage points compared with the employment rate of men in their late 20s. By contrast, the difference between the employment rates of women and men in their early $30 \mathrm{~s}$ is 40 percentage points. This gap is the main cause of the decrease in women's economic participation after their early 30s, and this phenomenon has existed since the early 2000s. Additionally, in the case of highly educated women, the period of career interruption increases, as depicted by the term "L-curve". Women who leave the labor market because of marriage, pregnancy, and childbirth finally return to work in their 40s. When re-entering the labor market, it is often found that employment differs from their prior career in terms of the form of employment and work conditions, resulting from a prolonged career break. In particular, the discrepancy between job position at the time of returning to work and the level of education is prominent for those women with higher education, and this may be an obstacle in women returning to the job market. Consequently, the employment rate of women with a college degree is only $60.5 \%$, lower than the OECD average of $79.3 \%$ by approximately 20 percentage points.

The active introduction of WFB practices is an important policy tool to increase the employment rate of women by potentially reducing the need for a prolonged career break; these policies may also raise the fertility rate by allowing a balanced work and family life to become more attainable. Table 1 describes South Korea's representative WFB policies.

Table 1. WFB policies in South Korea.

\begin{tabular}{ll}
\hline \multicolumn{1}{c}{ Title } & \multicolumn{1}{c}{ Description } \\
\hline Maternity or pregnancy leave & $\begin{array}{l}\text { A pregnant employee is provided with maternity leave of 90 days before } \\
\text { and after childbirth (first 60 days' paid leave of absence). }\end{array}$ \\
\hline Paternity leave & $\begin{array}{l}\text { A male employee is entitled to up to five days leave for his } \\
\text { spouse's childbirth. }\end{array}$ \\
\hline $\begin{array}{l}\text { Parental leave and working } \\
\text { hour reduction for childcare }\end{array}$ & $\begin{array}{l}\text { An employee who has a child aged under nine may apply for a leave of } \\
\text { absence for a period of up to 1 year (paid at 40\% of ordinary wages) or for } \\
\text { reduced working hours (15-30 h per week). }\end{array}$ \\
\hline Flexible working hours & $\begin{array}{l}\text { An employer should make an effort to offer reduced or flexible working } \\
\text { hours for employees' family care. }\end{array}$ \\
\hline Workplace childcare center & $\begin{array}{l}\text { A business with more than 300 full-time female employees or more than } \\
\text { 500 full-time employees should have a workplace childcare center or } \\
\text { operate it with nearby companies and should subsidize more than 50\% of } \\
\text { childrearing expenses. }\end{array}$ \\
\hline
\end{tabular}

According to the National Assembly Budget Office, the institutional maximum period of leave (including maternity or pregnancy leave and parental leave) a female worker can take in South Korea is 58.4 weeks, the 15th longest among 33 OECD countries [10]. Although WFB-related institutions in South Korea have been established at a similar level to those of other OECD members, however, the implementation rate of WFB policies is low. The National Assembly Budget Office reported a survey in 2013 on 1000 businesses that revealed that the implementation rates of maternity or pregnancy leave, paternity leave, parental leave, working hour reduction for childcare, flexible working hours, and workplace childcare centers were $77.2 \%, 19.4 \%, 21.0 \%, 8.4 \%, 12.5 \%$, and $39.1 \%$, respectively [10]. That is, the implementation rates of WFB policies other than maternity or pregnancy leave are low in practice. Moreover, the implementation rate of parental leave, a major WFB policy to prevent career interruption by helping workers return to work after childcare leave, stands at only $21 \%$. The importance of the parental leave policy was shown in a study by the National Assembly Budget 
Office, which with panel data on 1221 South Korean companies between 2007 and 2011 showed that only parental leave (among other WFB policies) significantly increased the ratio of women employee in the workplace [10]. Additionally, the implementation rate of workplace childcare centers, which is largely decided by a company's willingness and initiative to secure a location and budget for such a center, also showed a low level (39.1\%).

Some studies have attempted to explain why companies practice WFB policies. Goodstein, using survey data on 3000 US companies, showed that institutional pressure plays an important role in practicing WFB policies in each company and that the size of the company, the proportion of female employees, and the perceived cost and benefit of WFB practices affect institutional pressure on WFB practices [14]. Milliken and colleagues analyzed survey data on around 1000 human resources executives at companies throughout the United States and found that the WFB practicing rate is significantly different across industries (manufacturing industries showed a lower WFB practicing rate compared with the financial or healthcare sectors). In addition, companies are more likely to practice WFB policies when the issue is salient to senior human resources staff and thought likely to impact the organization's performance if unaddressed [15].

For the case of South Korea, the main causes of the low implementation rates of WFB policies are as follows: the cost and difficulty of hiring and retaining replacement workers, a company culture that is unfavorable for WFB policies, and problems with the location and budget for workplace childcare centers. Further, the implementation rates of WFB policies in SMEs and private corporations are lower than those in large and public companies. In particular, firm size had a large impact on the implementation rates of WFB policies, with the implementation rate of parental leave in businesses with greater than 300 employees reaching $68.6 \%$ compared with less than $10 \%$ at businesses with fewer than 30 employees [10]. Consequently, female workers are inevitably facing the dilemma of either having a child or working, which in turn has led to the current low fertility rate and low economic participation rate of women in South Korea [7].

\subsection{WFB Policies in OECD Countries}

In the 1980s, the OECD member countries with higher female employment rates showed lower fertility rates [7]. The correlation coefficient between the female employment rate and fertility rate was negative $(-0.40)$, and countries with the highest female employment rates (i.e., Sweden, Finland, Denmark, and Norway, which had an average participation rate of $66 \%$ ) showed a fertility rate of 1.65 on average, lower than the OECD average of 1.92. However, this correlation turned positive (correlation coefficient $=0.23$ ) as many countries actively adopted WFB policies including parental leave, financial support, flexible working hours, workplace childcare centers, public childcare services, and many others. In 2009, the female employment rates in Sweden, Finland, Denmark, and Norway exceeded $80 \%$ and the fertility rate for these four countries was 1.91, far higher than the OECD average of 1.68.

Various studies examine the effect of WFB policies on the fertility rate, mostly using panel data on OECD countries. Adsera analyzed the effect of paid and employment-protected leave on the fertility rate and reported that as the leave duration increases by one week, the fertility rate increases by around 0.006, which is a small rise [16]. This small increase partly stems from the fact that the entitlement of parental leave is conditional on employment, which makes men and women postpone childbirth (which has a negative effect on overall fertility) until they have established themselves in the labor market [7]. Financial transfers for childcare support are reported to have a positive and significant effect on the fertility rate. D'Addio and Mira d'Ercole reported that when the payment during parental leave increases by $1 \%$ of the average wage, the fertility rate increases by around 0.014 ; further, an increase in the disposable income of families with children by $10 \%$ through the tax/benefit system may raise the fertility rate by around 0.02 [17].

The effect of formal childcare services on fertility rates is also found to be high. Hilgeman and Butts reported that as the enrollment rates of formal childcare services increase by $15 \%$, the total fertility 
rate increases by 0.23 [18]. Workplace practices such as long working hours and working weeks make it harder to match work and care commitments and have been found to negatively affect fertility rates [19]. By contrast, part-time employment opportunities have a positive effect on fertility rates in OECD countries, especially among women with a higher level of educational attainment $[17,20]$.

\subsection{Literature Review}

Many studies have focused on the various effects of WFB practices on companies and workers. Yamamoto and Matsuura conducted a panel regression by using 1990s' panel data on Japanese companies to investigate the effect of WFB practices on productivity and turnover, and the results showed that in the case of large manufacturing companies, WFB practices lowered the turnover rate and thus improved productivity [21]. Ngo and colleagues used a structural equation model to analyze 2006 survey data on 180 multinational corporations in Hong Kong and suggested that the CEO's support is crucial in adopting WFB policies and that the introduction of WFB policies has a positive impact on the organizational climate such as trust among members, morale, rewards equitability, and leader credibility, eventually leading to positive consequences such as high performance in the market and a low turnover rate [22]. Russell and colleagues analyzed a 2003 survey of 5000 Irish workers and revealed that family-friendly policies such as flexible working hours lower work stress and work-life conflict. By contrast, it was found that telecommuting increases work stress and work-life conflict, indicating that telecommuters may be burdened by both work stress and housework [23]. Greenhaus and Parasuraman suggested that parental leave is an important WFB policy as it helps meet workers' need for childrearing and forms a positive organizational image [24].

The studies described above mainly analyzed various WFB policies by focusing on whether companies were implementing such policies and their employees' responses. However, with this approach, it could be difficult to quantify the value of WFB policies to employees, the purpose of the present study. There may be some discrepancy between the companies in which job seekers attain employment and the companies they prefer. In particular, in a serious unemployment crisis, job seekers are likely to work for a company that has work available rather than a company for which they would want to work [25]. In addition, some studies in the field of behavioral economics have reported that irrationality is observed more often in high-stakes decisions such as job selection [26,27]. There is therefore a limitation in analyzing job seekers' actual preferences by using data on revealed preferences that represent their actual choice of company. Revealed preference studies only provide precise estimates of the willingness to pay for goods when individuals have full and accurate information about the quality of the goods and when relevant markets are not plagued by market power and transaction costs [28]. However, in the job market, it is often found that job seekers do not have full information on goods (e.g., job specification) and that market power is on the side of the recruiter than the job seeker (especially when the unemployment rate is high). Additionally, there exist transaction costs that hamper efficient decisions in various forms (e.g., commuting distance and labor market regulations).

Because of this limitation, the present study used a choice experiment, a method that analyzes stated preferences, to investigate how preferences for companies change when WFB policies are implemented. To the best of our knowledge, this is the only study of this kind that has included major WFB policies as a company attribute, even though several studies have analyzed job selection by using choice experiments.

Baum and Kabst conducted a choice experiment on 130 German college and graduate students and took into account the following company attributes: work climate, security, flexible working hours availability, working schedule, training, salary, person-organization fit, promotion prospects, task attractiveness, and location [29]. Tumasjan and colleagues conducted a choice experiment about finding a job in a start-up company on 160 German college students and set the attributes of the start-up business as follows: flexibility of working, hierarchy, team climate, stock option, responsibility, task variety, leadership functions, learning curve, and entrepreneurial knowledge building [30]. Their findings revealed that such job seekers value a team climate and the early assignment of 
responsibilities. Brosi and Welpe carried out a choice experiment on 285 international postdocs looking for a job [31]. For postdocs, the major attributes that are important at work are relationship quality with mentor, scientific autonomy, research scholarships and funding, general training, and tenure track position availability. As a result, postdoctoral scholars identified the relationship quality with a scientific mentor and scientific autonomy as the most important attributes. Flaherty and Pappas analyzed what company attributes salespersons value, using a choice experiment on 96 US salespeople, and included the following company attributes: strategy, compensation, revenue source diversification, firm size, and management consideration of service quality [32].

As discussed above, previous studies have performed various choice experiments about job selection using different attributes depending on the purpose of each study to simulate hypothetical workplaces. For the choice experiment designed in this study, major WFB policies in South Korea were added to the company attributes suggested by previous studies.

\subsection{Research Questions}

By using the choice experiment method, we aim to answer these two research questions: how much benefit in monetary terms do various WFB practices provide to workers and does the benefit differ by the characteristics of job seekers? However, to conduct the choice experiment, it was difficult to consider all WFB policies since too many attributes on the choice options will make respondents' rational choice difficult. Hence, we choose two representative WFB policies: parental leave and workplace childcare centers. Considering its importance, parental leave was added as a representative WFB policy to the company attributes. The second WFB policy added was the existence of a workplace childcare policy. Providing a childcare program is largely decided by a company's willingness and initiative to secure a location and budget for such a center, and this reflects a company's focus on supporting workers' childcare post-infancy. We expect a positive and significant amount of benefits to be estimated from the choice experiment since demand for the policies are expected to be high in South Korea. We also expect significant differences in preferences for attributes according to individual characteristics such as gender, education, and income level. Additionally, in South Korea, since SMEs are mostly subcontractors of large companies, they have lower productivity and profitability [33,34]. Further, the rate of labor shortage in SMEs was $2.7 \%$ in 2014 compared with $1 \%$ in large companies, with employment in SMEs characterized by frequent turnover and short tenures; two-thirds of workers in SMEs stay for fewer than five years [35]. As such, SMEs are generally less desirable to employees compared with large companies. We thus tried to see whether this trend can be reversed by applying WFB policies in SMEs.

\section{Methodology}

\subsection{Survey Design}

To analyze the preferences of individuals for WFB policies in companies, it is necessary to build an experiment to suggest hypothetical situations in which various combinations of workplace attributes are presented from which respondents can choose. Thus, the present study conducted an analysis by adopting a discrete choice experiment based on consumers' stated preferences.

Adults aged over 20 consider various attributes when choosing a job. However, it is virtually impossible to consider every attribute and it is difficult to draw rational outcomes from respondents when every attribute is considered. Therefore, this study suggested five attributes based on the characteristics of a company, as shown in Table 2. Here, a respondent could express his/her preference by choosing the preferred alternative among hypothetical companies in which various combinations of the five attributes were suggested, with all other attributes being equal. 
Table 2. Attributes and levels used in the choice experiment.

\begin{tabular}{|c|c|c|c|}
\hline Attribute & Label & Definition & Attribute Level \\
\hline Salary & salary & Annual salary before tax. & $\begin{array}{l}20 \text { million won; } 25 \text { million won; } \\
30 \text { million won; } 35 \text { million won }\end{array}$ \\
\hline $\begin{array}{l}\text { Weekly } \\
\text { working hours }\end{array}$ & working_hours & Working hours per week. & $40 \mathrm{~h} /$ week; $60 \mathrm{~h} /$ week; $80 \mathrm{~h} /$ week \\
\hline Parental leave & parental_leave & $\begin{array}{l}\text { The scheme for which a worker can apply } \\
\text { and utilize to raise a child aged under nine } \\
\text { for a period up to one year. The company } \\
\text { must pay } 40 \% \text { of his / her ordinary wage } \\
\text { every month during this period. }\end{array}$ & $\begin{array}{l}\text { Unusable (0); Strongly encouraged } \\
\text { to utilize (1) }\end{array}$ \\
\hline $\begin{array}{l}\text { Workplace } \\
\text { childcare center }\end{array}$ & childcare_center & $\begin{array}{l}\text { Childcare center is installed within the } \\
\text { company or jointly operated with nearby } \\
\text { companies; more than } 50 \% \text { of the childcare } \\
\text { costs are subsidized. }\end{array}$ & None (0); In operation (1) \\
\hline Firm size & large_firm & $\begin{array}{l}\text { A company is defined as an SME if it has } \\
\text { capital of less than } 8 \text { billion won or fewer } \\
\text { than } 300 \text { full-time workers. Otherwise, it is } \\
\text { a large company. }\end{array}$ & SME (0); Large company (1) \\
\hline
\end{tabular}

Annual salary, weekly working hours, and firm size have been found to be important workplace attributes [29-32]. Additionally, the present study added the availability of parental leave and a workplace childcare center to the attributes to discern the effect of WFB policies.

The annual salary attribute was set to between 20 and 35 million won, taking into consideration the starting salaries in South Korean companies. The average salary for college graduates in 2015 was 30.5 million won, and 24.9 million won in the case of SMEs. South Korea's standard number of weekly working hours is 40 according to the labor law. However, as workload varies by company, the level was set between 40 and $80 \mathrm{~h}$ in this study. Parental leave was regarded as a dummy variable as some companies strongly encourage the scheme, while others are unable to implement it. The existence of a workplace childcare center was also considered to be a dummy variable since some companies have a childcare center and others do not. Firm size was divided into large companies and SMEs according to the number of full-time workers and amount of capital, and this was set as a dummy variable.

From the levels of each attribute in Table 2, 96 combinations are possible $(4 \times 3 \times 2 \times 2 \times 2=96)$. However, since it would be impossible to analyze respondents' preferences for all 96 possible alternatives, an orthogonal fractional factorial design that guarantees orthogonality among the levels of each attribute was used to draw 24 combinations. These combinations were then divided into eight choice sets, with three alternatives per group, and the survey was composed to ask respondents to choose their preferred alternative. In short, the survey was designed to let respondents choose their preferred company. The survey was conducted by using six types of questionnaires with different compositions. Table 3 presents an example of a discrete choice experiment. Respondents are asked to choose most preferred option among Company $A$ to $C$ in the last row, of which attributes level are drawn from combinations of hypothetical companies. Each respondent face eight choice sets of this kind.

Table 3. An example of a discrete choice experiment.

\begin{tabular}{lccc}
\hline & Company A & Company B & Company C \\
\hline 1. Annual salary (pre-tax) & 35 million won & 35 million won & 25 million won \\
2. Weekly working hours & $40 \mathrm{~h}$ & $80 \mathrm{~h}$ & $40 \mathrm{~h}$ \\
3. Parental leave & Unavailable & Strongly encouraged & Unavailable \\
4. Workplace childcare center & In operation & None & In operation \\
5. Firm size & SME & SME & Large company \\
Choose your preferred option & () & () & () \\
\hline
\end{tabular}


The present study commissioned a survey agency to conduct an online survey and survey data were collected over a 10-day period from 17 June to 26 June 2016. Considering the characteristics of the research related to WFB policies, 633 participants aged 19 and over from across the nation were included in the study in order to collect highly representative data. In addition, respondents were selected by using quota sampling to represent the actual composition of South Korea's population in terms of region (divided into 16 cities and provinces), gender, and age. Among 2285 people opened the surveying e-mail, 633 respondents completed questionnaire, and the response rate was $27.7 \%$. Since the 633 respondents chose from 24 alternatives, generating 15,192 units of data. Table 4 presents the distribution of respondents' characteristics.

Table 4. Characteristics of the survey respondents.

\begin{tabular}{cccc}
\hline \multirow{2}{*}{ Gender } & & Number of Samples & \% Share \\
\hline \multirow{3}{*}{ Age (years) } & Male & 320 & $50.6 \%$ \\
& Female & 313 & $49.4 \%$ \\
\hline \multirow{3}{*}{ Number of preschool children } & $19-29$ & 110 & $17.4 \%$ \\
& $30-39$ & 122 & $19.3 \%$ \\
& $40-49$ & 142 & $22.4 \%$ \\
& $50-59$ & 124 & $19.6 \%$ \\
Education level & $60-65$ & 135 & $21.3 \%$ \\
\hline \multirow{3}{*}{$\begin{array}{c}\text { Monthly household income } \\
\text { (Unit: thousand won) }\end{array}$} & 0 & 541 & $85.5 \%$ \\
& Less than high school & 67 & $10.6 \%$ \\
& More than university/college & 24 & $3.8 \%$ \\
& $0-2000$ & 1 & $0.2 \%$ \\
\hline & $2000-3000$ & 316 & $49.9 \%$ \\
& $3000-4000$ & 104 & $50.1 \%$ \\
\hline
\end{tabular}

\subsection{Hierarchical Bayesian Model}

The present study conducted a choice experiment by using data on stated preferences gathered by a public survey. A choice experiment is used in areas such as economics and business management as it discerns respondents' preferences more accurately by reproducing a process of choosing an alternative. Various methods can be used for a choice experiment, and this study adopted a hierarchical Bayesian model. This method, which reflects the heterogeneity of respondents, is a model that sets different coefficient vectors to represent respondents' preferences per attribute, according to the characteristics of respondents [36]. It was assumed that preferences for WFB policies vary depending on respondents' characteristics such as gender and level of education. Thus, a hierarchical Bayesian model was used to reflect this.

First, based on a random utility model, the utility individual $i$ receives from alternative $j$ can be classified into a deterministic term $\left(V_{i j}\right)$ and a stochastic term $\left(\varepsilon_{i j}\right)$ :

$$
U_{i j}=V_{i j}+\varepsilon_{i j}
$$

The deterministic term in Equation (1) can be represented by multiplying the variables $\left(x_{j}\right)$ that represent the attribute level of alternative $j$ affecting utility by the coefficient vector $\left(\beta_{i}\right)$, the value that respondent $i$ placed on the alternative: 


$$
U_{i j}=\sum \beta_{\mathbf{i}} x_{j}+\varepsilon_{i j}
$$

In a hierarchical Bayesian model, it is possible to estimate the parameters at an individual level, and the attribute coefficient vector $\left(\beta_{\mathbf{i}}\right)$ for consumer $i$ can be expressed by dividing it into the individual characteristic vector of the consumer $\left(\mathbf{z}_{\mathbf{i}}\right)$ and the parameter matrix $(\boldsymbol{\Gamma})$ as detailed in the following equation [37]:

$$
\boldsymbol{\beta}_{\mathbf{i}}=\Gamma \mathbf{z}_{\mathbf{i}}+\zeta_{i}, \zeta_{i} \sim N(0, \boldsymbol{\Sigma})
$$

In Equation (3), $\zeta_{i}$ is an error term, and a normal distribution with mean 0 and variance $\Sigma$ is assumed. $\Sigma$ is a matrix that represents the covariance between coefficients [37]. One of the benefits of the hierarchical Bayesian logit model is that it is possible to estimate preference distribution according to individual characteristics by linking the variable that represents individual characteristics to changes in individual attribute parameters. In other words, it is an extended form of the mixed logit model. It is assumed that the error term in Equation (2) follows the type 1 extreme value distribution to estimate the parameters. At this point, the probability of respondent $i$ choosing alternative $j$ is as follows:

$$
\operatorname{Pr}_{i}(j)=\frac{\exp \left(x_{j}^{\prime} \boldsymbol{\beta}_{\mathbf{i}}\right)}{\sum_{k} \exp \left(x_{k}^{\prime} \boldsymbol{\beta}_{\mathbf{i}}\right)}
$$

There is a traditional method of calculating maximum likelihood estimations by drawing a likelihood function from the above probability equation. However, this calculation is complicated and it often fails to calculate the sole maximum likelihood estimator, meaning that the Bayesian method is often now used in preference to estimate the parameters. In Bayesian analysis, a parameter's posterior distribution is calculated by combining its prior distribution for each parameter with the likelihood determined by the data. Therefore, a normal distribution and an inverse-Wishart distribution are assumed as prior distributions for $\Gamma$ and $\boldsymbol{\Sigma}$, respectively to estimate a hierarchical Bayesian model [37]:

$$
\begin{aligned}
& \boldsymbol{\Gamma} \sim N(\eta,) \\
& \boldsymbol{\Sigma} \sim W(\omega, \Omega)
\end{aligned}
$$

Along with the above assumption, as suggested by Allenby and Rossi [38], data are drawn in order from a conditional distribution by creating the following hierarchical structure. This process repeats until a parameter value converges to draw a distribution of the individual parameters:

$$
\begin{aligned}
& \Gamma \mid \Sigma, \beta_{\mathbf{i}} \\
& \Sigma \mid \beta_{\mathbf{i}}, \Gamma \\
& \beta_{\mathbf{i}} \mid \Gamma, \Sigma
\end{aligned}
$$

In the hierarchical Bayesian model, the number of parameters to be estimated increases by the number of individual characteristic variables multiplied by the number of attribute parameters. Thus, the probability that all parameters would be significant falls; however, it is possible to explain the demographic characteristics that affect the attributes based on the individual characteristic variables.

Meanwhile, the MWTP for each attribute can be drawn from the estimated coefficients. The MWTP is the price the individual would be willing to pay to maintain the same utility level as before when the amount or quality of a unit changes. The study measured the MWTP as the extent to which the respondent values each company attribute in terms of annual salary. Therefore, the MWTP for attribute $\mathrm{k}$ is calculated as follows:

$$
\operatorname{MWTP}_{k}=\frac{\partial U_{i j} / \partial x_{k}}{\partial U_{i j} / \partial x_{\text {salary }}}=\frac{\beta_{k}}{\beta_{\text {salary }}}
$$

Here, $\beta_{\text {salary }}$ means the coefficient values that respondents have for salary. 


\subsection{Analytical Strategy}

The hierarchical Bayesian model directly relates the demographic characteristics of respondents to the attribute coefficients. In this study, the number of preschool children, household income, gender, level of education, and age were selected as the respondents' characteristics that could affect the preference for each company attribute. The reason why the number of preschool children was chosen as an individual characteristic variable was that it is thought to be directly related to WFB policies. Previous studies have pointed out that household income affects women's job selection [10]. In addition, the study attempted to discern differences in the preference for WFB policies according to gender (women $=1$ ). As for the level of education, the dummy variable was coded 1 for college graduates and 0 otherwise, as it is considered that preference for WFB policies would change according to a respondent's education level. The number of highly educated women taking a career break to care for their children is increasing $[10,13]$. For age, the dummy variable was coded 1 for respondents in their 20s and 30s and 0 otherwise. As employees in their 20s and 30s are likely to shoulder the burden of childbirth and childrearing (at present or in the near future), they were included in the demographic characteristics. All the data related to the demographic characteristics of respondents are obtained from the survey conducted for choice experiment (which is explained in Section 3.1 survey design section).

Additionally, regional variables representing where respondents reside were included in the respondents' characteristics to take into account the effect of the residential environment on the preference for attributes (South Korea is divided into 16 cities and provinces and data from Statistics Korea were used as the regional variables). The variables included the ratio of career-interrupted women (i.e., women who had taken a career break) and the ratio of unemployment among women. The ratio of career-interrupted women was measured by the number of career-interrupted women/the number of unemployed women in a region, and this was used to examine the preference for WFB policies in regions where career interruption is common among women. The ratio of unemployment among women was measured by the unemployment rate of women/unemployment rate of men: the higher the rate, the lower is demand for female workers in a region. The following labels were used for each demographic variable: the number of preschool children (KIDS_U9), household income (HOUSEHOLD_INCOME), women (FEMALE), college graduates (EDU_UNIV), respondents in their 20s and 30s (AGE_2030), the ratio of career-interrupted women in a region (REG_INTERRUPT), and the ratio of the unemployment rate among women in a region (REG_UNEMP).

The software used for the estimation was the Sawtooth Software CBC Hierarchical Bayes Module (Version 5.5.2; Sawtooth Software: Orem, UT, USA) and it was assumed that every attribute follows a normal distribution. As the software requires level values to be specified for continuous variables, a unit of the variable "annual salary" was set as 5 million won and a unit of the variable "weekly working hours" was set as $20 \mathrm{~h}$.

Probability sampling was conducted 100,000 times for the 633 respondents in Markov chains by using Gibbs sampling, excluding the first 30,000 extraction values and analyzing the remaining 70,000 values. This is because some steps are needed for convergence toward the estimated values.

Individual utility is observed using Equation (2) and individual part-worth for each attribute is observed using Equation (3). In Equation (2), the company attributes used for the analyses are: $X_{\text {salary }}, X_{\text {working_hours }}, X_{\text {parental_leave, }}, X_{\text {childcare_center }}, X_{\text {large_firm, }}$ which represent annual salary, weekly working hours, the availability of parental leave, the availability of a workplace childcare center, and whether it is a large company, respectively. And in Equation (3), the individual characteristics affect the preference for each company attribute are:

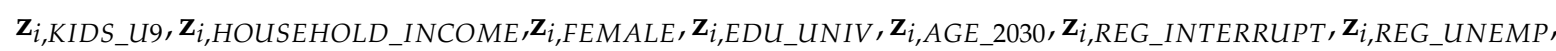
which represent the number of preschool children, household income, women, college graduates, respondents in their 20s and 30s, the regional ratio of career-interrupted women, and the regional ratio of the unemployment rate among women, respectively. Equation (3) is estimated for each company attribute. 


\section{Results and Discussion}

Table 5 presents the estimation results for the hierarchical Bayesian logit model in the discrete choice experiment. When the percent of draws for parameters that are positive is $>95 \%$ or $<5 \%$, it is regarded that these estimates are significantly different from zero, at or better than the $90 \%$ confidence level (two-sided test) [12]. The first row shows the estimates of Equation (2), which is individual utility; each column represents the estimates of Equation (3), which is the individual part-worth for each attribute.

Table 5. Estimation results for the hierarchical Bayesian multinomial logit model.

\begin{tabular}{|c|c|c|c|c|c|}
\hline & $\begin{array}{c}X_{\text {salary }} \\
\text { (Annual } \\
\text { Salary) }\end{array}$ & $\begin{array}{c}X_{\text {working_hours }} \\
\text { (Weekly Working } \\
\text { Hours) }\end{array}$ & $\begin{array}{c}X_{\text {parental_leave }} \\
\text { (Parental } \\
\text { Leave) }\end{array}$ & $\begin{array}{c}X_{\text {childcare_center }} \\
\text { (Workplace } \\
\text { Childcare Center) }\end{array}$ & $\begin{array}{c}X_{\text {large firm }} \\
\text { (Firm Size) }\end{array}$ \\
\hline Means $\left(\beta^{\prime} s\right)$ & $9.18^{* * *}$ & $-17.91^{* * *}$ & $10.65^{* * *}$ & $9.86^{* * *}$ & $2.26^{* * *}$ \\
\hline Intercept & -0.34 & 4.29 & 9.63 & $12.22 * *$ & 1.71 \\
\hline $\begin{array}{c}\Gamma_{K I D S \_U 9} \text { (Number of } \\
\text { preschool children) }\end{array}$ & 0.80 & -2.00 & $3.40 * *$ & 0.69 & -1.77 \\
\hline $\begin{array}{c}\Gamma_{\text {HOUSEHOLD_INCOME }} \\
\text { (Household income) }\end{array}$ & 0.24 & -0.33 & $-0.69 * *$ & 0.22 & $0.71^{* * *}$ \\
\hline$\Gamma_{F E M A L E}$ (Women) & $-1.36^{*}$ & -0.40 & $4.53^{* * *}$ & $2.31 * *$ & $-2.98^{* * *}$ \\
\hline $\begin{array}{c}\Gamma_{E D U_{\text {_UNIV }}(\text { College }}(\text { graduates })\end{array}$ & -0.37 & 0.40 & -1.13 & 1.10 & $2.64 * *$ \\
\hline$\Gamma_{A G E \_2030}(20 \mathrm{~s}$ and 30s $)$ & -0.18 & -2.12 & $3.41 * *$ & 0.40 & 1.63 \\
\hline $\begin{array}{c}\Gamma_{R E G_{I} I N T E R R U P T} \text { (Ratio of } \\
\text { career interrupted women } \\
\text { in a region) }\end{array}$ & $0.16^{*}$ & $-0.48^{* * *}$ & 0.04 & 0.03 & -0.06 \\
\hline $\begin{array}{c}\Gamma_{\text {REG_UNEMP }} \text { (Ratio of the } \\
\text { unemployment rate } \\
\text { among women in a region) }\end{array}$ & 0.44 & 6.98 & -0.64 & $-7.06^{*}$ & 0.16 \\
\hline
\end{tabular}

The estimation results in Table 5 show that the coefficients (means $\left(\beta^{\prime} s\right)$ ) for the five attributes are all statistically significant at the $1 \%$ significance level (the first row of Table 5). It was found that respondents preferred a large company $(+2.26)$ that provides a high annual salary $(+9.18)$, short weekly working hours $(-17.91)$, parental leave $(+10.65)$, and a workplace childcare center $(+9.86)$. This result is intuitive.

A characteristic of the hierarchical Bayesian method is that it can specifically estimate the preferences for each attribute according to the individual characteristics. Each column of Table 5 shows the effect of the individual characteristics on each attribute. We displayed the relevant numbers from Table 5 in the parentheses to explain the result as follows. Workers with a preschool child were found to be significantly more sensitive $(+3.40)$ to the availability of parental leave. Workers with a preschool child are already shouldering the burden of childrearing and their preference for parental leave, which would help them rear their child or have another, is therefore stronger than average. Meanwhile, it was found that the higher household income, the lower is the sensitivity to parental leave $(-0.69)$ and the higher is the sensitivity to the attribute of a "large company" (+0.71). It can be inferred from this result that as workers with high household incomes are able to afford alternative childrearers such as babysitters, or have the option of full-time childrearing without working [13], they are less sensitive to the availability of parental leave. Moreover, for workers with a low household income, if the number of earners in their household decreases because of childrearing, it is highly likely that they may fall into poverty [7]. Workers with a low household income would therefore be more sensitive to the availability of parental leave and the attributes that help them avoid career interruption. 
In addition, workers with a high income would prefer to work for a large company instead of an SME, where the prospects for growth and the opportunities for career development are relatively low [35].

From a gender perspective, it was found that women are more sensitive to the availability of parental leave $(+4.53)$ and a workplace childcare center $(+2.31)$ and less sensitive to annual salary $(-1.36)$ and firm size $(-2.98)$. These results clearly reflect the current situation for female employees in South Korea. The salary gap between men and women in 2011 was 37.5\%, the highest among OECD countries and more than double the OECD average of 15\% [4]. Irrespective of salary, women are likely to prefer workplaces that strongly encourage WFB policies in a society where striking a balance between work and family is hard to achieve. It can be argued that WFB policy support is therefore essential to increase women's economic participation rate. Workers with a college education were found to be sensitive to the size of the company (+2.64), indicating that the higher the level of education, the stronger the preference for a large company. Workers in their 20s and 30s, who are likely to face the reality of childbirth and childrearing, were found to be sensitive to parental leave $(+3.41)$, suggesting that the policy is critical for the younger generation's reconciliation of work and family life.

Regarding the effect of the regional variables, it was found that workers in regions where the ratio of career-interrupted women is high are sensitive to relatively high annual salary $(+0.16)$ and short working hours $(-0.48)$. Regions where the ratio of career-interrupted women is high are likely to have more single income households (mostly from husbands) and suffer from relatively long working hours. In this case, the utility that annual salary and reduced working hours provide would be huge. Respondents in regions where the ratio of the unemployment rate among women to the unemployment rate among men is relatively low were found to be sensitive to the provision of a workplace childcare center (-7.06). Regions where the unemployment rate of women is relatively low have high demand for female workers, and subsequently demand for workplace childcare centers is high.

The correlations between the marginal utilities of the attributes were also determined by using the individual parameters for the estimated attributes. Table 6 shows the Pearson correlation coefficients (ranging from -1 to 1 ) and significant levels for attributes. Although they are not strong, there is a negative correlation between annual salary and weekly working hours and a positive correlation between parental leave and a workplace childcare center. This may be interpreted as follows: workers who place high value on their annual salary tend to prefer short weekly working hours. It is likely that such workers work in sectors where long working hours such as overtime and weekend work are prevalent. Hence, the increase in utility according to a decrease of one unit in working hours is larger. By contrast, workers who place high value on parental leave tend to prefer the provision of a workplace childcare center. It was found that workers who play the role of childrearer show high levels of preference for various WFB policies.

Table 6. Correlations among the attribute coefficients.

\begin{tabular}{cccccc}
\hline & $\begin{array}{c}\text { Annual } \\
\text { Salary }\end{array}$ & $\begin{array}{c}\text { Weekly Working } \\
\text { Hours }\end{array}$ & Parental Leave & $\begin{array}{c}\text { Workplace } \\
\text { Childcare Center }\end{array}$ & $\begin{array}{c}\text { Large } \\
\text { Company }\end{array}$ \\
\hline $\begin{array}{c}\text { Annual salary } \\
\text { Weekly working hours }\end{array}$ & $1.00^{* * *}$ & $-0.29^{* * *}$ & -0.03 & 0.02 & $0.13^{* *}$ \\
$\quad \begin{array}{c}\text { Parental leave } \\
\text { Workplace childcare center }\end{array}$ & & $1.00^{* * *}$ & $-0.10^{* *}$ & $-0.18^{* * *}$ & $-0.10^{* *}$ \\
Large company & & & $1.00^{* * *}$ & $0.29^{* * *}$ & $-0.14^{* *}$ \\
\hline
\end{tabular}

Note: ${ }^{* *}$ significance level of $5 \%,{ }^{* * *}$ significance level of $1 \%$.

The WTP for company attributes can be calculated according to Equation (7); for the continuous variables, namely annual salary and weekly working hours, WTP was measured by taking one unit to represent 5 million won and $20 \mathrm{~h}$, respectively. The results from the WTP analysis show that respondents are willing to pay 488,000 won $\left(=\left(\frac{-17.91}{20}\right) /\left(\frac{9.18}{5,000,000}\right)\right)$ per year for a decrease of an hour in weekly working hours. That is, an hour of weekly working time has a value of 488,000 won of annual salary. This can be converted into an hourly wage of approximately 9385 won per hour, 
which is 1.56 times South Korea's 2016 minimum wage, 6030 won. Meanwhile, respondents' WTP for parental leave and a workplace childcare center are 5,802,000 won $\left(=10.65 /\left(\frac{9.18}{5,000,000}\right)\right)$ and 5,371,000 won $\left(=9.86 /\left(\frac{9.18}{5,000,000}\right)\right)$, respectively per year. In other words, the availability of parental leave provides utility equivalent to an increase of 5,802,000 won in annual salary and the provision of a workplace childcare center has an effect equivalent to an increase of 5,371,000 won. This finding implies that a company that implements both WFB policies offers 11,173,000 won more than a company that does not. This amounts to approximately $37 \%$ of the 2015 average starting salary for South Korea's college graduates [39]. Although the implementation of WFB policies such as parental leave and a workplace childcare center incurs a cost to companies (hiring and retaining replacement workers and installing and operating a workplace childcare center), it provides employees with high utility, leading to higher levels of satisfaction among workers and a lower turnover rate. Turnover from an SME to a large company has utility equivalent to an increase of $1,230,000$ won $\left(=2.26 /\left(\frac{9.18}{5,000,000}\right)\right)$, in annual salary, meaning that job seekers prefer large companies to SMEs. However, this difference is small compared with the WTP according to the implementation of WFB policies, and those SMEs implementing such policies may therefore be preferred by job seekers to large companies lacking such policies. This tendency will be more notable for women, workers in their 20s and 30s, and workers with a preschool child.

Therefore, the study results suggest that SMEs that experience a chronic labor shortage should consider the implementation of WFB policies. In the case of SMEs, it may be difficult for them to install their own workplace childcare centers because of their small size. In this case, it is necessary to consider government support programs such as the SME Joint Workplace Childcare Center Support Project that subsidizes operating expenses and up to $90 \%$ of installation costs through a contest held by the Korea Workers' Compensation and Welfare Service [40].

\section{Summary and Conclusions}

South Korea is facing the combined challenges of a low employment rate among women and a low fertility rate. The active implementation of WFB policies offers a potential solution to these problems. The present study conducted a choice experiment, asking 633 respondents their stated preferences for hypothetical companies to quantify the amount of utility that WFB policies provide to workers. Workers' preferences for company attributes vary depending on individual characteristics, so to take this into account, a hierarchical Bayesian model was employed. The findings of the study were as follows. First, the availability of parental leave offers utility equivalent to an increase of 5,802,000 won in annual salary and the provision of a workplace childcare center has an effect equivalent to an increase of 5,371,000 won in annual salary. Second, those of low income, women, the younger generation, and workers with a preschool child are more sensitive to WFB policies. Third, large companies are preferred to SMEs, but this reverses when WFB policies such as parental leave and a workplace childcare center are in operation. Fourth, regions where the number of single income households is high have a relatively high preference for shorter working hours, while regions where the unemployment rate of women is low have a relatively high preference for a workplace childcare center.

The theoretical implication of this study is suggesting a framework with which to quantify the WTP of WFB policies. WFB policies are known to benefit employees and employers $[8,9,16-19,23]$. However, the current study suggested a framework to be used to consider various WFB policies jointly and provide WTP estimates in monetary terms. In practice, this study can therefore be useful for the government and companies to compare the benefits from and costs of WFB policies as well as setting the amount of government support. Further, since this study considers the heterogeneity of individuals, the results can be helpful for building and designing more focused support policies (e.g., highly educated female workers suffering from career interruption).

According to the results of the present study, WFB policies provide workers with great utility. The high WTP for WFB policies reflects the current imbalance between work and family in South Korea. 
The government should continue to actively support WFB policies to enhance social sustainability. Companies also have sufficient incentives to implement WFB policies to attract and retain talented workers or to offer an additional benefit when there is a limitation in monetary rewards.

However, this study suffers from some limitations. As it aimed to examine the effect of major WFB policies such as parental leave and workplace childcare centers for the general public, it was unable to assess the exact effect of other WFB policies for more specific groups (e.g., how women in their 30s with children perceive the value of paternity leave). Future studies that investigate a mixture of WFB policies aimed at different groups of people might result in a more accurate understanding of the benefits of such WFB practices. Further, the results concerning the monetary values of WFB policies presented in this study were only inferred from the hypothetical choice experiment rather than being actual monetary values.

Acknowledgments: This paper was supported by Konkuk University in 2016.

Author Contributions: All authors contributed equally to collecting the data as well as designing and writing this article. Further, they have all read and approved the final manuscript.

Conflicts of Interest: The authors declare no conflicts of interest.

\section{References}

1. OECD. Pensions at a Glance; OECD: Paris, France, 2013.

2. OECD. Labour Force Statistics; OECD: Paris, France, 2016.

3. OECD. Ageing in Cities; OECD: Paris, France, 2015.

4. OECD. Strengthening Social Cohesion in Korea; OECD: Paris, France, 2013.

5. Shin, K.-A. Work-life balance and working hours. Democr. Soc. Policy Stud. 2009, 16, 176-212. (In Korean)

6. Hyundai Research Institute. The Solution to Dissolve the Gap between the Desired Number of Children and the Number of Children Born; Hyundai Research Institute: Seoul, Korea, 2010. (In Korean)

7. OECD; Doing Better for Families; OECD: Paris, France, 2011.

8. Frone, M.R.; Yardley, J.K. Workplace family-supportive programmes: Predictors of employed parents' importance ratings. J. Occup. Organ. Psychol. 1996, 69, 351-366. [CrossRef]

9. Starrels, M.E. The evolution of workplace family policy research. J. Fam. Issues 1992, 13, 259-278. [CrossRef]

10. National Assembly Budget Office. Analyzing the Effect of Work-Life Balance Policies; National Assembly Budget Office: Seoul, South Korea, 2014. (In Korean)

11. Lu, L.; Cooper, C. Handbook of Research on Work-Life Balance in Asia; Edward Elgar: Cheltenham, UK, 2015.

12. Orme, B. CBC/HB v5 Software for Hierarchical Bayes Estimation for CBC Data; Sawtooth Software, Inc.: Sequim, WA, USA, 2009.

13. National Assembly Budget Office. Investigating the Social Cost of Career Interruption of Female Worker; National Assembly Budget Office: Seoul, South Korea, 2014. (In Korean)

14. Goodstein, J.D. Institutional pressures and strategic responsiveness: Employer involvement in work-family issues. Acad. Manag. J. 1994, 37, 350-382. [CrossRef]

15. Milliken, F.J; Martines, L.L.; Morgan, H. Explaining organisational responsiveness to work-family issues: The role of human resource managers as issue interpreters. Acad. Manag. J. 1998, 41, 580-592. [CrossRef]

16. Adsera, A. Changing fertility rates in developed countries: The impact of labor market institutions. J. Popul. Econ. 2004, 17, 17-43. [CrossRef]

17. D'Addio, A.; Mira d'Ercole, M. Trends and Determinants of Fertility Trends: The Role of Policies; OECD Social, Employment and Migration Working Papers, No. 27; OECD Publishing: Paris, France, 2005. Available online: www.oecd.org/els/workingpapers (accessed on 10 May 2017).

18. Hilgeman, C.; Butts, C. Women's employment and fertility: A welfare regime paradox. Soc. Sci. Res. 2009, 38, 103-117. [CrossRef] [PubMed]

19. Luci, A.; Thévenon, O. The Impact of Family Policy Packages on Fertility Trends of OECD Countries; Population American Association: Washington, DC, USA, 2011.

20. Del Boca, D.; Pasqua, S.; Pronzato, C. Market work and motherhood decisions in contexts. Oxf. Econ. Pap. 2009, 61, 147-171. [CrossRef] 
21. Yamamoto, I.; Matsuura, T. Effect of work-life balance practices on firm productivity: Evidence from Japanese firm-level panel data. BE J. Econ. Anal. Policy 2014, 14, 1677-1708. [CrossRef]

22. Ngo, H.-Y.; Foley, S.; Loi, R. Family friendly work practices, organizational climate, and firm performance: A study of multinational corporations in Hong Kong. J. Organ. Behav. 2009, 30, 665-680. [CrossRef]

23. Russell, H.; O'Connell, P.J.; McGinnity, F. The impact of flexible working arrangements on work-life conflict and work pressure in Ireland. Gend. Work Organ. 2009, 16, 73-97. [CrossRef]

24. Greenhaus, J.H.; Parasuraman, S. A work-nonwork interactive perspective of stress and its consequences. J. Organ. Behav. Manag. 1987, 8, 37-60. [CrossRef]

25. Marimon, R.; Zilibotti, F. Unemployment vs. mismatch of talents: Reconsidering unemployment benefits. Econ. J. 1999, 109, 266-291. [CrossRef]

26. Field, E. Educational debt burden and career choice: Evidence from a financial aid experiment at NYU Law School. Am. Econ. J. Appl. Econ. 2009, 1, 1-21. [CrossRef]

27. Krieshok, T.S.; Black, M.D.; McKay, R.A. Career decision making: The limits of rationality and the abundance of non-conscious processes. J. Vocat. Behav. 2009, 75, 275-290. [CrossRef]

28. Earnhart, D. Combining revealed and stated preference methods to value environmental amenities at residential locations. Land Econ. 2001, 77, 12-29. [CrossRef]

29. Baum, M.; Kabst, R. Conjoint implications on job preferences: The moderating role of involvement. Int. J. Hum. Res. Manag. 2013, 24, 1393-1417. [CrossRef]

30. Tumasjan, A.; Strobel, M.; Welpe, I. Employer brand building for start-ups: Which job attributes do employees value most? Z. Betr. 2011, 81, 111-136. [CrossRef]

31. Brosi, P.; Welpe, I. Employer branding for universities: What attracts international postdocs? J. Bus. Econ. 2015, 85, 817-850. [CrossRef]

32. Flaherty, K.E.; Pappas, J.M. Job selection among salespeople: A bounded rationality perspective. Ind. Mark. Manag. 2004, 33, 325-332. [CrossRef]

33. Oh, I.; Heshmati, A.; Baek, C.; Lee, J.-D. Comparative analysis of plant dynamics by size: Korean manufacturing. Jpn. Econ. Rev. 2009, 60, 512-538. [CrossRef]

34. Oh, I.; Lee, J.-D.; Heshmati, A. Total factor productivity in Korean manufacturing industries. Glob. Econ. Rev. 2008, 37, 23-50. [CrossRef]

35. Lee, E. Improvement of Government Support Policy for 2015 to Eliminate Labor Shortage of SMEs; Institute for International Trade, Korea International Trade Association: Seoul, Korea, 2014. (In Korean)

36. Allenby, G.M.; Rossi, P.E. Marketing models of consumer heterogeneity. J. Econom. 1998, 89, 57-78. [CrossRef]

37. Allenby, G.M.; Ginter, J.L. Using extremes to design products and segment markets. J. Mark. Res. 1995, 32, 392-403. [CrossRef]

38. Allenby, G.M.; Rossi, P.E. Hierarchical Bayes models. In The Handbook of Marketing Research: Uses, Misuses, and Future Advances; Grover, R., Vriens, M., Eds.; Sage Publications: London, UK, 2006; pp. 418-440.

39. Kim, Y.-S. The Average Salary of College Graduates Is 30.48 Million Won ... Large Companies Are 1.5 Times Bigger than SMEs; Yonhap News: Seoul, Korea, 2005. Available online: http:/ /www.yonhapnews.co.kr/bulletin/ 2015/04/16/0200000000AKR20150416056100003.HTML (accessed on 10 May 2017). (In Korean)

40. Ministry of Employment and Labor. SME Joint Workplace Childcare Center Support Project; Ministry of Employment and Labor: Sejong, Korea, 2016. (In Korean)

(C) 2017 by the authors. Licensee MDPI, Basel, Switzerland. This article is an open access article distributed under the terms and conditions of the Creative Commons Attribution (CC BY) license (http://creativecommons.org/licenses/by/4.0/). 